\title{
Engineering microbial consortia to enhance biomining and bioremediation
}

\author{
Karl D. Brune and Travis S. Bayer* \\ Centre for Synthetic Biology and Innovation, Division of Molecular Biosciences, Imperial College London, London, UK
}

Edited by:

Weiwen Zhang, Tianjin University,

China

Reviewed by:

Romy Chakraborty, Lawrence

Berkeley National Lab, USA

Lei Chen, Tianjin University, China

*Correspondence:

Travis S. Bayer, Centre for Synthetic Biology and Innovation, Division of Molecular Biosciences, Imperial

College London, London SW7 2AZ,

UK.e-mail: t.bayer@imperial.ac.uk
In natural environments microorganisms commonly exist as communities of multiple species that are capable of performing more varied and complicated tasks than clonal populations. Synthetic biologists have engineered clonal populations with characteristics such as differentiation, memory, and pattern formation, which are usually associated with more complex multicellular organisms. The prospect of designing microbial communities has alluring possibilities for environmental, biomedical, and energy applications, and is likely to reveal insight into how natural microbial consortia function. Cell signaling and communication pathways between different species are likely to be key processes for designing novel functions in synthetic and natural consortia. Recent efforts to engineer synthetic microbial interactions will be reviewed here, with particular emphasis given to research with significance for industrial applications in the field of biomining and bioremediation of acid mine drainage.

Keywords: acid mine drainage, bioleaching, biomining, bioremediation, microbial consortia, synthetic biology, synthetic microbial consortia

\section{INTRODUCTION}

Natural microbial consortia are known to facilitate a wide range of complex tasks such as inter-species biofilm formation that allows microorganisms to persist in inhospitable environments (Keller and Surette, 2006). Syntrophic degradation of complex molecules also allows two species to complete metabolic reactions from which neither species would gain energy without the cooperation of the other (Zhou et al., 2011). Consortia play a crucial role in the human gut microbiome (Kau et al., 2011) and are known to heavily influence the ecological dynamics of the marine community (Giovannoni and Vergin, 2012). Humans have made use of natural consortia for millennia and selected them for better performance or desired properties in areas such as dairy processing (Reid, 2012), beer, and wine fermentation (Di Maio et al., 2012), and more recently in biogas processing (Lynd et al., 2002) and biomining (Rawlings, 2007).

The field of synthetic biology has developed a wide range of highly engineered clonal populations of bacteria to perform complex tasks such as differentiation (Süel et al., 2006), memory (Ham et al., 2008), counting (Friedland et al., 2009), and pattern formation (Liu et al., 2011a) as well as industrial applications such as production of antimalarial drug precursors (Ro et al., 2006), fuel like long-chain alcohols (Atsumi et al., 2008), and biosensors for arsenic in drinking water (Stocker et al., 2003). The construction and analysis of synthetic gene circuits has not only provided us with new tools for genetic engineering but has given deeper insight into naturally occurring gene circuits, their evolution, architectures, and properties as well (Sprinzak and Elowitz, 2005; Çağatay et al., 2009; Elowitz and Lim, 2010).

Considering that most synthetic circuits have been engineered in clonal populations it has been proposed that engineering synthetic consortia may allow for more complex tasks in industrial applications (Brenner et al., 2008; Sabra et al., 2010;
Momeni etal., 2011). Synthetic consortia may empower scientists and engineers to cultivate and make use of some of the $99 \%$ percent of microbes that have not been cultured yet and also to elucidate the role of the many genes that have yet unknown function(s), which might well be of particular relevance in microbial consortia (Wintermute and Silver, 2010). So far several proof-ofconcept and industrial synthetic consortia have been engineered and reviewed (Brenner et al., 2008; Rollié et al., 2012); highlighted by a recent review focusing on engineered communication and biofuel processing (Shong et al., 2012).

The industrial practice of biomining (Olson et al., 2003) and bioremediation of heavy metal contaminations (Haferburg and Kothe, 2010) could potentially benefit from synthetic consortia as natural consortia have been shown to play crucial roles in these processes. This review focuses on using microbial isolates to construct consortia that would otherwise not be found together in Nature and discusses the potential use of genetically engineered species in bioremediation and biomining processes.

\section{MICROBIAL CONSORTIA IN BIOMINING BIOLOGICAL PROCESSES IN METAL RECOVERY}

Biomining entails the use of acidophilic microbes to facilitate the recovery process of metals from sulfide minerals in the processes of bioleaching and biooxidation. Biooxidation is the enrichment of metals, particularly gold, by mobilization and thus removal of interfering metal sulfides from ores bearing the precious metals (Rohwerder et al., 2003). Bioleaching is the solubilization of metals of interest such as cobalt, copper, and nickel from sulfide minerals. The two processes are industrially well established and are commercially applied worldwide (Rawlings, 2007). The microbes found in these environments are (extreme) acidophiles growing at a $\mathrm{pH}$ of 3 or lower and span a wide range of different phyla. The majority belong to the bacterial and archaea domains; 
however, unicellular eukaryotes have also been reported (Baker and Banfield, 2003; Bonnefoy and Holmes, 2011).

The impact of microbial consortia in bioleaching, particularly in copper recovery, is widely recognized in literature and industry (Olson et al., 2003; Rohwerder et al., 2003). Microorganisms oxidize both sulfur and iron of sulfide minerals, such as pyrite. It is generally accepted that leaching takes place via an "indirect" mechanism, which can be divided into the "contact" and "non-contact" mode (Baker and Banfield, 2003; Rohwerder et al., 2003). The "indirect" mechanism assumes that chemoautotrophic iron-oxidizing microorganisms like Acidithiobacillus ferrooxidans or Leptospirillum ferrooxidans generate ferric ions by oxidation of ferrous iron (Rawlings, 2002). During the "non-contact" mode planktonic microbes oxidize aqueous ferrous ions to ferric ions, which in turn attack the mineral surface by chemical oxidation. The "contact" mode assumes a small reaction space between the microbial cell wall and the mineral surface where ferric ions are concentrated in biofilms for a localized attack of the sulfide mineral. Either mode yields different intermediate and final sulfur species depending on the ore leached. The thiosulfate mechanism applies for acid-insoluble metal sulfides such as molybdenite $\left(\mathrm{MoS}_{2}\right)$ and pyrite $\left(\mathrm{FeS}_{2}\right)$, and eventually yields sulfate $\left(\mathrm{SO}_{4}{ }^{2-}\right)$ as the main end product. The so-called polysulfide mechanism applies for acid-soluble metal sulfides such as arsenopyrite (FeAsS) and chalcopyrite $\left(\mathrm{CuFeS}_{2}\right)$, eventually yielding elemental sulfur as the main end product (Rawlings, 2002; Rohwerder et al., 2003). Accumulating sulfur layers may act as a leaching inhibitor because of sterically impeding the ferric ion attack on the ore and thus affecting the growth of iron-oxidizing microbes. Chalcopyrite leaching is particularly sensitive to inactivation by formation of jarosite layers as a function of redox potential and is thus one of the most recalcitrant ore to leach (Viramontes-Gamboa et al., 2010). These sulfur layers however can be oxidized to soluble sulfate by sulfur-oxidizing bacteria such as Acidithiobacillus caldus or Acidithiobacillus thiooxidans (Dopson and Lindstrom, 1999; Sand et al., 2001; Mangold et al., 2011). Hence naturally occurring consortia of autotrophic iron-oxidizing microbes and sulfur-oxidizing microbes have been proposed to be symbiotic, potentially mutualistic (Rawlings et al., 1999) or at least synergetic in substrate use (Johnson, 1998; Roger Morin in Donati and Sand, 2007, 136).

\section{COMMUNICATION IN NATURAL BIOMINING CONSORTIA}

Research on extracellular polymeric substances (EPS) of A. ferrooxidans suggests that biofilm formation, which is crucial for the contact leaching mechanism, leads to an increase in redox potential and thus increase leaching rates as iron ions are trapped in the EPS (Sand and Gehrke, 2006). It is known that communication plays a major role in microbial biofilm formation (McDougald et al., 2012). The model bioleaching organism A. ferrooxidans produces and responds to compounds of the acyl homoserine lactones (AHLs) family used in auto-inducer 1 (AI-1) type quorum-sensing (QS) system (Keller and Surette, 2006) as well as to the c-diGMP pathway (Hengge, 2009), which is also employed in QS. Two loci have been identified encoding for AHL synthases, the classical LuxI-type afeI acyl synthase (Farah et al., 2005; Rivas et al., 2005) and act which is related to the LPA acyltransferase family
(Rivas et al., 2007). Both systems are involved in response to iron and sulfur substrates respectively, though act may be alternatively (or additionally) involved in cell membrane formation via fatty acid synthesis which is yet to be elucidated (Valdés et al., 2008). Recent studies also suggest a role of AHL-mediated QS in resistance toward high copper concentrations (Wenbin et al., 2011). The existence of a c-di-GMP pathway in A. ferrooxidans was discovered by analysis of its genome sequence (Ruiz et al., 2007). The pathway has been shown to respond to changes of the energetic substrate (iron and sulfur) as well as to the lifestyle of the bacteria (planktonic or biofilm-associated growth) by determination of intracellular c-di-GMP levels (Ruiz et al., 2011). Even though AHL type QS systems are absent from A. caldus and A. thiooxidans as inferred by genome analysis (Valdés et al., 2008), sequence analysis of the psychrotolerant Acidithiobacillus ferrivorans SS3 performed in our group (unpublished) suggests presence of an AHL type QS as we were able to identify an act homolog with $84 \%$ identity giving rise to the possibility for inter-species communication. Potential inter-species communication may also occur via the more common c-di-GMP QS. Related genes and the signaling compound were identified and isolated from $A$. caldus and $A$. thiooxidans (Castro et al., 2009). As biofilm formation is crucial for the leaching process it may be suitable to modulate AHL- and c-di-GMP levels to optimize attachment to ore particles for example, which may enhance bioleaching processes. However, although the existence of the above-mentioned pathways suggests that QS regulated biofilm formation plays a role in mineral solubilization, further experiments are required to prove this assumption.

\section{CONSORTIA OF NATURALLY OCCURRING SPECIES}

Whereas most studies have been performed on pure cultures of A. ferrooxidans, many early studies characterized mixed cultures of bioleaching organisms, mainly due to the difficulty in full separation of species in natural consortia (Harrison, 1984). Hence naturally occurring consortia have been characterized as well as defined consortia of naturally occurring organisms in order to elucidate mechanisms and synergies that improve the leaching process (Rawlings and Johnson, 2007). The impact of natural consortia was shown to be profound. In one example, a synergetic effect was observed by Qiu et al. (2005) during chalcopyrite leaching with a defined consortia of $A$. ferrooxidans and A. thiooxidans. The mixed culture was more efficient at leaching chalcopyrite than the pure cultures. The authors concluded that co-culture reduced the formation of inhibiting jarosite layers by the generation of sulfuric acid due to sulfur oxidation of A. thiooxidans.

Employment of heterotrophic acidophiles to remove inhibiting organic compounds that accumulate during growth led to acceleration of the leaching process. This was attributed to the increased growth rate of $A$. ferrooxidans while it was co-cultured with the heterotroph Acidiphilium acidophilum (Liu et al., 2011b).

Further examples for advantages of consortia are increased acid production (Okibe and Johnson, 2004), improved attachment to mineral surfaces (Noël et al., 2010), increased growth, and leaching rates (Bacelar-Nicolau and Johnson, 1999; Okibe and Johnson, 2004; Fu et al., 2008; Liu et al., 2011d; Naghavi et al., 2011). 
While some of the above-mentioned consortia are most likely to occur in nature, engineering defined natural consortia has opened new possibilities for enhanced bioleaching (Rawlings and Johnson, 2007). Considering that researchers can choose from a wide range of microbes from different geographic locations, there is potential for additional, yet unexplored synergetic effects that may arise as these artificially assembled microbial consortia would not be encountered in nature. The use of consortia assembled from naturally occurring species is furthermore interesting because they would not be considered genetically modified and are hence not susceptible to regulatory procedures.

\section{CONSORTIA OF NATURAL AND ENGINEERED SPECIES}

To our best knowledge, hybrid consortia consisting of genetically engineered and naturally occurring bioleaching bacteria have not been reported so far. Even though some bioleaching organisms, in particular those of the Acidithiobacillus genus have been successfully transformed, genetic manipulations are difficult as transformation efficiencies are extremely low (Kusano et al., 1992; Peng et al., 1994). In fact only two knockouts (Liu et al., 2000; Wang et al., 2012) and two expression mutants have been reported in the scientific literature. One rus overexpressing A. ferrooxidans strain and another expressing the mer determinant for a mercury resistant A. caldus strain (Chen et al., 2011; Liu et al., 2011c). Once more suitable transformation protocols have been developed, it may be feasible to modulate QS signals with engineered microbes by either attenuating or amplifying natural signals or sending artificial signals to promote biofilm formation or mobilization respectively as recently demonstrated with engineered E. coli cells (Hong et al., 2012). Interestingly, it has been shown that once an initial consortia has been established, the power of evolution can be used to drive novel species interactions potentially resulting in increased consortia stability and productivity (Hansen et al., 2007).

Ultimately, engineered consortia could be deployed in industrial scale heap and tank leaching operations to improve bioleaching and biooxidation processes. However, as highlighted by Rawlings and Johnson (2007) it is crucial to consider that the tailored consortia have to compete with other microbes and their associated consortia in the non-sterile leaching environment. Usually this is not too much of a problem as the fastest growing species is usually the one leading to increased leaching. Depending on the ore leached, however, in particular chalcopyrite ores, high redox potential, which is associated with dominant iron-oxidizing microbes such as A. ferrooxidans or L. ferrooxidans is not appreciated as the continuous leaching process will stall after an initial high rate of recovery (Ohata et al., 2010).

Furthermore, hybrid consortia might be used to culture many of the yet uncultured microbes. There are abundant microbes in acid environments which are still to be cultured, characterized and their role in the ecosystem to be elucidated (Baker et al., 2010).

\section{MICROBIAL CONSORTIA IN ACID MINE DRAINAGE BIOREMEDIATION}

One major environmental consequence of industries such as mining, galvanic processing, and construction is the possibility of acid rock drainage (ARD) or in the particular case of mining, acid mine drainage (AMD), where wastewater effluents and mine run-off are not properly managed. AMD may occur where access of oxidants to sulfide minerals, in particular pyrite, is facilitated due to mining operations as the surface area of the minerals is increased (Baker and Banfield, 2003). Both inorganic and biological reactions drive the acidification and heavy metal contamination of water due to oxidation of sulfide minerals (Ma and Banfield, 2011). The biological reactions account for the gross of AMD production with estimates as high as 75\% (Baker and Banfield, 2003). The same organisms and consortia that are used in biomining operations are the major contributors to AMD generation, though AMD biofilms are mainly dominated by the chemoautotrophic Nitrospirae phylum bacteria Leptospirillum spp. (Gadd, 2009; Wilmes et al., 2009). AMD is dealt with usually in two ways, either by migration control or source control in case the axiom "prevention is better than cure" is feasible (Johnson and Hallberg, 2005; Das et al., 2009). In industrial environments AMD is usually managed at source by neutralization of wastewater and run-offs in rather costly abiotic neutralization processes with limestone. Therefore, the above-mentioned microbes and their biofilm environments are an interesting target for AMD management. Abiotic AMD mitigation control options as well as biological remediation processes have been recently reviewed (Johnson and Hallberg, 2005; Gadd, 2009) and are beyond the scope of this review. We will therefore focus on the few examples of biological AMD source control of AMD and discuss potential future applications.

Johnson et al. (2007) reported the use of heterotrophic acidophiles to colonize pyrite prior to exposure to iron-oxidizing bacteria to reduce dissolution of the mineral. The process, named "bioshrouding" was capable of decreasing the dissolution rate between 57 and 75\%. This was presumably due to the heterotrophs' biofilm that impeded attachment of the autotrophic iron-oxidizer. It remains to be seen if this approach is viable in industrial scale operations as iron-oxidizing autotrophs may outcompete the heterotrophs in the non-sterile environment though their growth could be impeded by the necessary supply of artificial carbon sources such as yeast extracts to foster the growth of the heterotrophs, which is known to inhibit growth of autotrophic organisms (Harrison, 1984).

Eukaryotic organisms such as algae and fungi have been reported in aquatic AMD environments, and could be engineered to mitigate AMD. Their natural role and potential application in bioremediation of AMD has been recently reviewed (Das et al., 2009). Engineering these eukaryotes for quenching of QS may be a very attractive option as resistance to quenching is unlikely to evolve (Defoirdt et al., 2010) and a broad range of quenching mechanisms are available. One example is the production of AI-1 type interfering halogenated furanones secreted by the algae Delisea pulchra (Czajkowski and Jafra, 2009). These small molecules mimic bacterial QS compounds and thus interfere with bacterial signaling and biofilm colonization.

Furthermore, the use of tailored bacteriophages and viruses (Lu and Collins, 2007) could potentially impede biofilm formation of autotrophs as naturally occurring viruses have been reported in AMD environments (Andersson and Banfield, 2008; Denef et al., 2010). Engineers employing this approach would have to 
contend with bacterial defense mechanisms. The CRISPR (for Clustered Regularly Interspaced Short Palindromic Repeats) interference mechanisms are one such strategy bacteria and archaea use to evade phage treatment. Exogenous DNA is inactivated and processed to small elements of $\sim 30$ bp due to proteins encoded by the CRISPR-associated (cas) genes. These are then incorporated into the CRISPR locus from which they are constitutively expressed, processed and remain with an accompanying flanking region. The resulting CRISPR RNA (crRNA) binds to complementary RNA or DNA molecules and recruits Cas proteins to cleave the targeted nucleic acid depending on the organism (Marraffini and Sontheimer, 2010). This system has been used to rationally engineer crRNA-mediated mRNA cleavage in the extreme thermophilic archaea Pyrococcus furiosus using the native $\mathrm{Cmr}$ protein (Hale et al., 2012). Desired beneficial strains and consortia could therefore be potentially rendered "immune" by CRISPR engineering.

\section{CONCLUSIONS AND FUTURE PERSPECTIVES}

The ability to design and manipulate microbial consortia may allow biologists and engineers to enhance mineral recovery in biomining processes beyond the yields and productivities observed with naturally occurring consortia. Furthermore, it is likely that

\section{REFERENCES}

Andersson, A. F., and Banfield, J. F. (2008). Virus population dynamics and acquired virus resistance in natural microbial communities. Science 320, 1047-1050.

Atsumi, S., Hanai, T., and Liao, J. C. (2008). Non-fermentative pathways for synthesis of branched-chain higher alcohols as biofuels. Nature 451, 86-89.

Bacelar-Nicolau, P., and Johnson, D. B. (1999). Leaching of pyrite by acidophilic heterotrophic ironoxidizing bacteria in pure and mixed cultures. Appl. Environ. Microbiol. 65, 585-590.

Baker, B. J., and Banfield, J. F. (2003). Microbial communities in acid mine drainage. FEMS Microbiol. Ecol. 44, 139-152.

Baker, B. J., Comolli, L. R., Dick, G. J., Hauser, L. J., Hyatt, D., Dill, B. D., Land, M. L., VerBerkmoes, N. C., Hettich, R. L., and Banfield, J. F. (2010). Enigmatic, ultrasmall, uncultivated Archaea. Proc. Natl. Acad. Sci. U.S.A. 107, 8806-8811.

Bonnefoy, V., and Holmes, D. S. (2011). Genomic insights into microbial iron oxidation and iron uptake strategies in extremely acidic environments. Environ. Microbiol. doi: 10.1111/ j.1462-2920.2011.02626.x [Epub ahead of print].

Brenner, K., You, L., and Arnold, F. H. (2008). Engineering microbial consortia: a new frontier in synthetic biology. Trends Biotechnol. 26, 483-489.
Çağatay, T., Turcotte, M., Elowitz, M. B., Garcia-Ojalvo, J., and Süel, G. M. (2009). Architecture-dependent noise discriminates functionally analogous differentiation circuits. Cell 139, 512-522.

Castro, M., Ruíz, L. M., Barriga, A., Jerez, C. A., Holmes, D. S., and Guiliani, N. (2009). C-di-GMP pathway in biomining bacteria. Adv. Mat. Res. 71-73, 223-226.

Chen, D., Lin, J., Che, Y., Liu, X., and Lin, J. (2011). Construction of recombinant mercury resistant Acidithiobacillus caldus. Microbiol. Res. 166, 515-520.

Czajkowski, R., and Jafra, S. (2009). Quenching of acyl-homoserine lactone-dependent quorum sensing by enzymatic disruption of signal molecules. Acta Biochim. Pol. 56, $1-16$.

Das, B. K., Roy, A., Koschorreck, M., Mandal, S. M., Wendt-Potthoff, K., and Bhattacharya, J. (2009). Occurrence and role of algae and fungi in acid mine drainage environment with special reference to metals and sulfate immobilization. Water Res. 43, 883-894.

Defoirdt, T., Boon, N., and Bossier, P. (2010). Can bacteria evolve resistance to quorum sensing disruption? PLoS Pathog. 6, e1000989. doi: 10.1371/journal.ppat.1000989

Denef, V. J., Mueller, R. S., and Banfield, J. F. (2010). AMD biofilms: using model communities to study microbial evolution and ecological

synthetic consortia will also seep into other industrial sectors, which are currently mainly abiotic processes as microbial consortia are capable of more complex behaviors due to the combined properties of the individual organisms and the additional layers of regulation and adaptation to changing conditions.

The engineering of consortia will also be aided by the further characterization of the diverse species in bioleaching environments, which may have unique metabolic and physiological features. Prime candidates are the abundant archaea in biomining processes, which have not yet been subject to thorough research and are an untapped field of biological resources for industrial applications. The design and construction of synthetic and mixed microbial consortia will not only become a powerful tool in optimizing industrial processes but will also give us an insight into the evolution and emergence of naturally occurring microbial consortia. This will foster our understanding of higher-level system organization that is indispensible for designing complex functions.

\section{ACKNOWLEDGMENTS}

The authors would like to thank Axel Nyström for a critical reading of the manuscript. Research on microbial consortia in the Bayer lab is funded by EPSRC, BBSRC, and the Rio Tinto Centre for Advanced Mineral Recovery.

complexity in nature. ISME J. 4, 599-610.

Di Maio, S., Polizzotto, G., Di Gangi, E., Foresta, G., Genna, G., Verzera, A., Scacco, A., Amore, G., and Oliva, D. (2012). Biodiversity of indigenous Saccharomyces populations from Old Wineries of SouthEastern Sicily (Italy): preservation and economic potential. PLoS ONE 7, e30428. doi: 10.1371/journal. pone. 0030428

Donati, E. R., and Sand, W. (2007). Microbial Processing of Metal Sulfides. Dordrecht: Springer.

Dopson, M., and Lindstrom, E. B. (1999). Potential role of Thiobacillus caldus in arsenopyrite bioleaching. Appl. Environ. Microbiol. 65, 36-40.

Elowitz, M., and Lim, W. A. (2010). Build life to understand it. Nature 468, 889-890.

Farah, C., Vera, M., Morin, D., Haras, D., Jerez, C. A., and Guiliani, N. (2005). Evidence for a functional quorum-sensing type AI-1 system in the extremophilic bacterium Acidithiobacillus ferrooxidans. Appl. Environ. Microbiol. 71, 7033-7040.

Friedland, A. E., Lu, T. K., Wang, X., Shi, D., Church, G., and Collins, J. J. (2009). Synthetic gene networks that count. Science 324, 1199-1202.

Fu, B., Zhou, H., Zhang, R., and Qiu, G. (2008). Bioleaching of chalcopyrite by pure and mixed cultures of Acidithiobacillus spp. and Leptospirillum ferriphilum. Int. Biodeter. Biodegr. 62, 109-115.
Gadd, G. M. (2009). Metals, minerals and microbes: geomicrobiology and bioremediation. Microbiology 156, 609-643.

Giovannoni, S. J., and Vergin, K. L. (2012). Seasonality in ocean microbial communities. Science 335 , 671-676.

Haferburg, G., and Kothe, E. (2010). Metallomics: lessons for metalliferous soil remediation. Appl. Microbiol. Biotechnol. 87, 1271-1280.

Hale, C. R., Majumdar, S., Elmore, J., Pfister, N., Compton, M., Olson, S., Resch, A. M., Glover, C. V. C., Graveley, B. R., Terns, R. M., and Terns, M. B. (2012). Essential features and rational design of CRISPR RNAs that function with the Cas RAMP module complex to cleave RNAs. Mol. Cell. 45, 292-302.

Ham, T. S., Lee, S. K., Keasling, J. D., and Arkin, A. P. (2008). Design and construction of a double inversion recombination switch for heritable sequential genetic memory. PLoS ONE 3, e2815. doi: 10.1371/journal. pone. 0002815

Hansen, S. K., Rainey, P. B., Haagensen, J. A. J., and Molin, S. (2007). Evolution of species interactions in a biofilm community. Nature 445 , 533-536.

Harrison, A. P. (1984). The acidophilic thiobacilli and other acidophilic bacteria that share their habitat. Annu. Rev. Microbiol. 38, 265-292.

Hengge, R. (2009). Principles of c-diGMP signalling in bacteria. Nat. Rev. Microbiol. 7, 263-273. 
Hong, S. H., Hegde, M., Kim, J., Wang, X., Jayaraman, A., and Wood, T. K. (2012). Synthetic quorumsensing circuit to control consortial biofilm formation and dispersal in a microfluidic device. Nat. Commun. 3 , 613.

Johnson, D. B. (1998). Biodiversity and ecology of acidophilic microorganisms. FEMS Microbiol. Ecol. 27, 307-317.

Johnson, D. B., and Hallberg, K. B. (2005). Acid mine drainage remediation options: a review. Sci. Total. Environ. 338, 3-14.

Johnson, D. B., Yajie, L., and Okibe, N. (2007). "Bioshrouding" - a novel approach for securing reactive mineral tailings. Biotechnol. Lett. 30, 445-449.

Kau, A. L., Ahern, P. P., Griffin, N. W., Goodman, A. L., and Gordon, J. I. (2011). Human nutrition, the gut microbiome and the immune system. Nature 474, 327-336.

Keller, L., and Surette, M. G. (2006). Communication in bacteria: an ecological and evolutionary perspective. Nat. Rev. Microbiol. 4, 249-258.

Kusano, T., Sugawara, K., Inoue, C., Takeshima, T., Numata, M., and Shiratori, T. (1992). Electrotransformation of Thiobacillus ferrooxidans with plasmids containing a mer determinant. J. Bacteriol. 174, 6617-6623.

Liu, C., Fu, X., Liu, L., Ren, X., Chau, C. K. L., Li, S., Xiang, L., Zeng, H., Chen, G., Tang, L.-H., Lenz, P., Cui, X., Huang, W., Hwa, T., and Huang, J. D. (2011a). Sequential establishment of stripe patterns in an expanding cell population. Science 334, 238-241.

Liu, H., Yin, H., Dai, Y., Dai, Z., Liu, Y., Li, Q., Jiang, H., and Liu, X. (2011b). The co-culture of Acidithiobacillus ferrooxidans and Acidiphilium acidophilum enhances the growth, iron oxidation, and $\mathrm{CO} 2$ fixation. Arch. Microbiol. 193, 857-866.

Liu, W., Lin, J., Pang, X., Cui, S., Mi, S., and Lin, J. (2011c). Overexpression of rusticyanin in Acidithiobacillus ferrooxidans ATCC19859 increased $\mathrm{Fe}(\mathrm{II})$ oxidation activity. Curr. Microbiol. 62, 320-324.

Liu, Y., Yin, H., Zeng, W., Liang, Y., Liu, Y., Baba, N., Qiu, G., Shen, L., Fu, X., and Liu, X. (2011d). The effect of the introduction of exogenous strain Acidithiobacillus thiooxidans A01 on functional gene expression, structure and function of indigenous consortium during pyrite bioleaching. Bioresour. Technol. 102, 8092-8098.

Liu, Z., Guiliani, N., Appia-Ayme, C., Borne, F., Ratouchniak, J., and Bonnefoy, V. (2000). Construction and characterization of a recA mutant of Thiobacillus ferrooxidans by marker exchange mutagenesis. J. Bacteriol. 182, 2269-2276.

Lu, T. K., and Collins, J. J. (2007). Dispersing biofilms with engineered enzymatic bacteriophage. Proc. Natl. Acad. Sci. U.S.A. 104, 11197-11202.

Lynd, L. R., Weimer, P. J., van Zyl, W. H., and Pretorius, I. S. (2002). Microbial cellulose utilization: fundamentals and biotechnology. Microbiol. Mol. Biol. Rev. 66, 506-577.

Ma, S., and Banfield, J. F. (2011). Micron-scale $\mathrm{Fe}^{2+} / \mathrm{Fe}^{3+}$, intermediate sulfur species and $\mathrm{O}_{2}$ gradients across the biofilm-solutionsediment interface control biofilm organization. Geochim. Cosmochim. Acta 75, 3568-3580.

Mangold, S., Valdés, J., Holmes, D. S., and Dopson, M. (2011). Sulfur metabolism in the extreme acidophile Acidithiobacillus caldus. Front. Microbiol. 2:17. doi: 10.3389/ fmicb.2011.00017

Marraffini, L. A., and Sontheimer, E. J. (2010). CRISPR interference: RNAdirected adaptive immunity in bacteria and archaea. Nat. Rev. Genet. 11, 181-190.

McDougald, D., Rice, S. A., Barraud, N., Steinberg, P. D., and Kjelleberg, S. (2012). Should we stay or should we go: mechanisms and ecological consequences for biofilm dispersal. Nat. Rev. Microbiol. 10, 39-50.

Momeni, B., Chen, C.-C., Hillesland, K. L., Waite, A., and Shou, W. (2011). Using artificial systems to explore the ecology and evolution of symbioses. Cell. Mol. Life Sci. 68, 1353-1368.

Naghavi, N. S., Emami, Z. D., and Emtiazi, G. (2011). Synergistic copper extraction activity of Acidithiobacillus ferrooxidans isolated from copper coal mining areas. Asian J. Appl. Sci. 4, 447-452.

Noël, N., Florian, B., and Sand, W. (2010). AFM \& EFM study on attachment of acidophilic leaching organisms. Hydrometallurgy 104, 370-375.

Ohata, A., Manabe, M., and ParadaValdecantos, P. A. (2010). United States Patent: 7700343 - Sulfuroxidizing bacteria and their use in bioleaching processes for sulfured copper minerals. Available at: http:// patft.uspto.gov/netacgi/nph-Parser? Sect $2=$ PTO $1 \&$ Sect $2=$ HITOFF $\& p=1$ $\& \mathrm{u}=/$ netahtml/PTO/search-bool. $\mathrm{html} \& \mathrm{r}=1 \& \mathrm{f}=\mathrm{G} \& \mathrm{l}=50 \& \mathrm{~d}=$ PALL\& RefSrch $=$ yes\&Query $=$ PN/7700343 (Accessed March 28, 2012).

Okibe, N., and Johnson, D. B. (2004). Biooxidation of pyrite by defined mixed cultures of moderately thermophilic acidophiles in
pH-controlled bioreactors: significance of microbial interactions. Biotechnol. Bioeng. 87, 574-583.

Olson, G. J., Brierley, J. A., and Brierley, C. L. (2003). Bioleaching review part B: progress in bioleaching: applications of microbial processes by the minerals industries. Appl. Microbiol. Biotechnol. 63, 249-257.

Peng, J. B., Yan, W. M., and Bao, X. Z. (1994). Plasmid and transposon transfer to Thiobacillus ferrooxidans. J. Bacteriol. 176, 2892-2897.

Qiu, M., Xiong, S., Zhang, W., and Wang, G. (2005). A comparison of bioleaching of chalcopyrite using pure culture or a mixed culture. Miner. Eng. 18, 987-990.

Rawlings, D. E. (2002). Heavy metal mining using microbes. Annu. Rev. Microbiol. 56, 65-91.

Rawlings, D. E. (2007). Biomining. Berlin: Springer.

Rawlings, D. E., and Johnson, D. B. (2007). The microbiology of biomining: development and optimization of mineral-oxidizing microbial consortia. Microbiology 153, 315-324.

Rawlings, D. E., Tributsch, H., and Hansford, G. S. (1999). Reasons why "Leptospirillum"-like species rather than Thiobacillus ferrooxidans are the dominant iron-oxidizing bacteria in many commercial processes for the biooxidation of pyrite and related ores. Microbiology (Reading, Engl.) 145(Pt 1), 5-13.

Reid, A. J. (2012). Adapting to domesticity. Nat. Rev. Microbiol. 10, 163.

Rivas, M., Seeger, M., Holmes, D. S., and Jedlicki, E. (2005). A Luxlike quorum sensing system in the extreme acidophile Acidithiobacillus ferrooxidans. Biol. Res. 38, 283-297.

Rivas, M., Seeger, M., Jedlicki, E., and Holmes, D. S. (2007). Second acyl homoserine lactone production system in the extreme acidophile Acidithiobacillus ferrooxidans. Appl. Environ. Microbiol. 73, 3225-3231.

Ro, D.-K., Paradise, E. M., Ouellet, M., Fisher, K. J., Newman, K. L., Ndungu, J. M., Ho, K. A., Eachus, R. A., Ham, T. S., Kirby, J., Chang, M. C., Withers, S. T., Shiba, Y., Sarpong, R., and Keasling, J. D. (2006). Production of the antimalarial drug precursor artemisinic acid in engineered yeast. Nature 440 , 940-943.

Rohwerder, T., Gehrke, T., Kinzler, K., and Sand, W. (2003). Bioleaching review part A: progress in bioleaching: fundamentals and mechanisms of bacterial metal sulfide oxidation. Appl. Microbiol. Biotechnol. 63, 239-248.
Rollié, S., Mangold, M., and Sundmacher, K. (2012). Designing biological systems: Systems Engineering meets Synthetic Biology. Chem. Eng. Sci. 69, 1-29.

Ruiz, L. M., Castro, M., Barriga, A., Jerez, C. A., and Guiliani, N. (2011). The extremophile Acidithiobacillus ferrooxidans possesses a c-di-GMP signalling pathway that could play a significant role during bioleaching of minerals. Lett. Appl. Microbiol. 54, 133-139.

Ruiz, L. M., Sand, W., Jerez, C. A., and Guiliani, N. (2007). Cdi-GMP pathway in Acidithiobacillus ferrooxidans: analysis of putative diguanyl atecyclases (DGCs) and phosphodiesterases (PDEs) bifunctional proteins. Adv. Mat. Res. 20-21, 551-555.

Sabra, W., Dietz, D., Tjahjasari, D. and Zeng, A.-P. (2010). Biosystems analysis and engineering of microbial consortia for industrial biotechnology. Eng. Life Sci. 10, 407-421.

Sand, W., and Gehrke, T. (2006). Extracellular polymeric substances mediate bioleaching/biocorrosion via interfacial processes involving iron(III) ions and acidophilic bacteria. Res. Microbiol. 157, 49-56.

Sand, W., Gehrke, T., Jozsa, P.-G., and Schippers, A. (2001). (Bio)chemistry of bacterial leaching - direct vs. indirect bioleaching. Hydrometallurgy 59 , 159-175.

Shong, J., Jimenez Diaz, M. R., and Collins, C. H. (2012). Towards synthetic microbial consortia for bioprocessing. Curr. Opin. Biotechnol. doi: 10.1016/j.copbio.2012.02.001 [Epub ahead of print].

Sprinzak, D., and Elowitz, M. B. (2005).

Reconstruction of genetic circuits. Nature 438, 443-448.

Stocker, J., Balluch, D., Gsell, M., Harms, H., Feliciano, J., Daunert, S., Malik, K. A., and van der Meer, J. R. (2003). Development of a set of simple bacterial biosensors for quantitative and rapid measurements of arsenite and arsenate in potable water. Environ. Sci. Technol. 37, 47434750 .

Süel, G. M., Garcia-Ojalvo, J., Liberman, L. M., and Elowitz, M. B. (2006). An excitable gene regulatory circuit induces transient cellular differentiation. Nature 440, 545-550.

Valdés, J., Pedroso, I., Quatrini, R., and Holmes, D. S. (2008). Comparative genome analysis of Acidithiobacillus ferrooxidans, A. thiooxidans and A. caldus: insights into their metabolism and ecophysiology. Hydrometallurgy 94, 180-184. 
Viramontes-Gamboa, G., Peña-Gomar, M. M., and Dixon, D. G. (2010). Electrochemical hysteresis and bistability in chalcopyrite passivation. Hydrometallurgy 105, 140-147.

Wang, H., Liu, X., Liu, S., Yu, Y., Lin, J., Lin, J., Pang, X., and Zhao, J. (2012). Development of a markerless gene replacement system for Acidithiobacillus ferrooxidans and construction of a pfkB mutant. Appl. Environ. Microbiol. 78, 18261835.

Wenbin, N., Dejuan, Z., Feifan, L., Lei, Y., Peng, C., Xiaoxuan, Y., and Hongyu, L. (2011). Quorum-sensing system in Acidithiobacillus ferrooxidans involved in its resistance to $\mathrm{Cu}^{2+}$. Lett. Appl. Microbiol. 53, 84-91.

Wilmes, P., Simmons, S. L., Denef, V. J., and Banfield, J. F. (2009). The dynamic genetic repertoire of microbial communities. FEMS Microbiol. Rev. 33, 109-132.

Wintermute, E. H., and Silver, P. A. (2010). Dynamics in the mixed microbial concourse. Gene. Dev. 24, 2603-2614.

Zhou, J., He, Q., Hemme, C. L., Mukhopadhyay, A., Hillesland, K., Zhou, A., He, Z., Van Nostrand, J. D., Hazen, T. C., Stahl, D. A.,
Wall, J. D., and Arkin, A. P. (2011). How sulphate-reducing microorganisms cope with stress: lessons from systems biology. Nat. Rev. Microbiol. 9, 452-466.

Conflict of Interest Statement: The authors declare that the research was conducted in the absence of any commercial or financial relationships that could be construed as a potential conflict of interest.

Received: 10 April 2012; accepted: 17 May 2012; published online: 05 June 2012.
Citation: Brune KD and Bayer TS (2012) Engineering microbial consortia to enhance biomining and bioremediation. Front. Microbio. 3:203. doi: 10.3389/fmicb.2012.00203

This article was submitted to Frontiers in Microbiotechnology, Ecotoxicology and Bioremediation, a specialty of Frontiers in Microbiology.

Copyright (c) 2012 Brune and Bayer. This is an open-access article distributed under the terms of the Creative Commons Attribution Non Commercial License, which permits non-commercial use, distribution, and reproduction in other forums, provided the original authors and source are credited. 